\title{
Virtual Academic Units within UK Infrastructure for Research that Benefits Infants, Children and Young People
}

\author{
Andrew N Williams* \\ Virtual Academic Unit, Northampton General Hospital, Northampton, UK
}

I believe that Virtual Academic Units or their equivalent are an extremely cost effective means of augmenting research capacity in areas which previously would not have been done and bringing in new voices, not only from healthcare professionals, but also from patients and carers which would otherwise have not been heard. As a UK paediatrician, I was deeply surprised that the 2018 Royal College of Paediatrics and Child Health 'Turning the tide 5 years on' does not mention 'virtual Biomedical Research Units and Centres' and further was not mentioned in a recent review of child health research $[1,2]$. The establishment of such centres had been specifically recommended in the seminal 2012 Report 'Turning the Tide: Harnessing the power of child health research' [3].

We in Northampton established a Virtual Academic Unit (VAU) in 2004, and published our experience of its first 10 years experience in Archives in 2015 [4].

Among the articles published through the VAU there is 'Ethical Research Involving Children'. (2013) UNICEF, which predates the College own Children's and Young People's Child Health Research Charter [5].

The Virtual Academic Unit is continuing to collaborate on and publish in clinical child health research to this day $[6,7]$. In terms of paediatric clinical neurology/neurodisability it has been involved in long term studies published in EXOSC3 and OPA1 for patients under the care of my Department $[8,9]$. However, it has remained totally unfunded with no allocated research time in spite of every possible endeavour to address this. More recently, in a lateral step it worked with Together for Short Lives in showing a short film 'The Boudiccae' at the Houses of Parliament in October 2018 as part of a successful campaign leading to increased NHS England Children Hospice funding now written into the NHS Long Term Plan.

Certainly working within the United Kingdom, we have to be pragmatic and recognise that with present and future increasing pressures within the National Health Service (NHS) having any research time within a job plan is seen by most NHS managers as an unproductive luxury given the immediate pressing necessities of delivering a clinical service that remains very much under resourced. Working within District General Hospitals, research becomes an even more distant priority. Although undertaking clinical research is recognised as being central to good paediatric practice, one has to ask questions as to how it can be delivered outside teaching centres in this context [10].

As my 2015 article relates 'A VAU has its place and in a present and future environment where resources are continuing to be constrained, a method of working that allows something meaningful to be produced, from where previously nothing could be expected at all. ...Some realistic mechanism translating into sustained funding for VAUs would be very helpful' [4].

\section{References}

1. Hunter L, Greenough A, Modi N (2018) Turning the tide 5 years on. Royal College of Paediatrics and Child Health, London.

2. Whitty CJM (2018) Building UK infrastructure for research that benefits infants, children and young people. Archives of Disease in Childhood.

3. (2012) Turning the Tide: Harnessing the power of child health research. Royal College of Paediatrics and Child Health.

4. Williams AN (2015) A virtual academic unit--the first 10 years. Arch Dis Child Educ Pract Ed 100: 164-165.

5. Williams AN (2013) Facilitating future benefit when a participant has a degenerative illness and cannot give consent. In: Graham $\mathrm{A}$, Powell $\mathrm{M}$, Taylor $\mathrm{N}$, et al. Ethical research involving children. UNICEF Office of Research-Innocenti, Florence, 118-119.

6. Global Research on Developmental Disabilities Collaborators (2018) Developmental disabilities among children younger than 5 years in 195 countries and territories, 1990-2016: A systematic analysis for the Global Burden of Disease Study 2016. Lancet Glob Health 6: e1100-e1121.

7. Williams AN, Mold B, Kilbey L, et al. (2018) Forty years of

*Corresponding author: Andrew N Williams, Virtual Academic Unit, CDC, Northampton General Hospital, Northampton, UK

Accepted: August 10, 2019

Published online: August 12, 2019

Citation: Williams AN (2019) Virtual Academic Units within UK Infrastructure for Research that Benefits Infants, Children and Young People. J Pediatr Neurol Neurosci 3(1):41-42 
referrals and outcomes to a UK Child Development Centre (CDC): Has demand plateaued?. Child Care Health Dev 44: 364-369.

8. Eggens VR, Barth PG, Niermeijer JM, et al. (2014) EXOSC3 mutations in pontocerebellar hypoplasia type 1: Novel mutations and genotype-phenotype correlations. Orphanet J Rare Dis 9: 23.
9. Liao Chunyan, Ashley N, Diot Alan, et al. (2017) Dysregulated mitophagy and mitochondrial organisation in optic atrophy due to OPA1 mutations. Neurology 88: 131-142.

10. Davies HT, Phillips B, Preston J, et al. (2019) Making research central to good paediatric practice. Arch Dis Child 104: 385-388. 